\title{
Attachment, self-esteem, and socio-emotional adjustment: There is more than just the mother
}

\author{
Karine Verschueren
}

Catholic University in Leuven, Belgium

For many years, attachment researchers have pleaded for a more systematic study of the role of both parental attachment figures for children's development. Yet, studies examining attachment to both parents have remained the exception rather than the rule. The dominant focus on mothers as attachment figures is likely influenced by societal and cultural factors shaping Bowlby's early theorizing. The current socio-cultural context has clearly changed. Although mothers, on average, still spend more time in caregiving activities than do fathers, differences in maternal and paternal participation in child rearing have gradually decreased (Yeung, Sandberg, Davis-Kean, \& Hofferth, 2001). Focusing on mothers only would thus provide an incomplete account of children's attachment experiences in today's families. Attachment theory and research need to take a broader approach, taking into account the multiple attachment figures that play a role in children's lives.

\section{The Key Role of Attachment in the Development of Self}

The study by Bureau, Deneault and Yurkowski (this issue) addresses this need by investigating the unique and joint predictive value of preschool attachment to mother and father for socio-emotional adjustment in middle childhood. One of its main contributions is that it focuses on a key premise of attachment theory, namely that the quality of parental attachment shapes the formation of children's representational models of self. This effect on children's feelings and cognitions about the self is considered important as it is assumed to provide one of the main pathways explaining the influence of attachment quality across 
multiple developmental domains, such as social relationships, behavioral adaptation, and school adjustment. Through their day-to-day interactions with attachment figures, children come to internalize a sense of being more or less worthy and valuable (i.e., they develop a higher or lower self-esteem), which guides their behavior and perceptions in such a way as to fulfill itself (Ainsworth, 1990). Despite its central place in attachment theory, surprisingly few empirical studies have investigated the relation between early parent-child attachment quality and children's self-esteem, and even fewer studies have included both parents in this inquiry and looked at longer-term effects. Accordingly, Bureau and colleagues should be commended for addressing this gap.

\section{Relevant Insights for Later Socio-Emotional Functioning}

The study yields several relevant insights into the unique and combined role of mother-child and father-child attachment for later socio-emotional functioning. First, it provides further support for the role of attachment in the development of the self, by relying on an implicit assessment of self-esteem (i.e., a name liking measure). In that way, it corroborates and extends previous cross-sectional and longitudinal research that used other self-esteem assessments, such as child direct self-reports, indirect puppet interviews, and teachers' or independent observers' ratings of behavioral manifestations of self-esteem (Cassidy, 1988; Goodvin, Meyer, Thompson, \& Hayes, 2008; Pinto, Veríssimo, Gatinho, Santos, \& Vaughn, 2015; Verschueren, Marcoen, \& Schoefs, 1996). Second, it adds to the accumulating evidence that an insecure attachment to both parents amplifies the risk for socio-emotional problems (e.g., Kochanska \& Kim, 2013; Verschueren \& Marcoen, 1999). Bureau and colleagues show, for example, that secure attachment to both parents decreased the risk for low self-esteem and increased the likelihood of good (but not perfect) selfevaluations. Third, the study supports the developmental importance of preschool father-child attachment quality for child self-esteem and externalizing problems in middle childhood. 
Unexpectedly, however, neither self-esteem nor internalizing and externalizing symptoms were (uniquely) related with the quality of preschool attachment to mother. The findings thus call for the use of multiple assessments of self-esteem and socio-emotional adaptation, concurrently and prospectively, at multiple points in time, as this will allow examining whether any early effects of mother-child attachment on self-esteem (if present) have waned over time. Also, the findings call for the inclusion of other contextual variables that may modulate the effects of mother-child attachment on children's socio-emotional functioning.

Overall, this study has again failed to find any evidence for primacy or dominance of mother-child attachment. Both conceptually and empirically, it is thus hard to argue that attachment research can suffice with investigating the mother-child relationship only.

\section{Some Broader Questions and Future Directions}

More broadly, this study and related research raise important issues that provide interesting avenues for future scholarly work.

First, scholars have suggested that, although mothers and fathers both play a significant role as attachment figure, they may adopt different functions. Specifically, the 'safe haven' function of attachment, referring to the provision of comfort and reassurance when the child is stressed or upset, may be more prominent among mothers. In contrast, the 'secure base' function of attachment, implying the provision of support and encouragement when the child explores the wider social and non-social environment, may be more typical among fathers (Bretherton, 2010; Grossman et al., 2002; Kerns, Mathews, Koehn, Williams, \& Siener-Ciesla, 2015; Verschueren \& Marcoen, 1999). Accordingly, the developmental sequelae of differences in the quality of attachment to mother and father may differ (Steele \& Steele, 2005). In our previous work we showed, for instance, that children's inner feelings of worthiness were predicted more strongly by mother-child attachment representations, whereas 
their (lack of) exploration of the outer social world was related more strongly to father-child attachment representations (Verschueren \& Marcoen, 1999). To explain these differential effects we proposed that "mothers are (somewhat) more likely to play the role of caregiver and soother and to fulfill the child's need for comfort, nurturance, and affection ... [whereas] fathers are (somewhat) more likely to play the role of "playmate" and to fulfill the child's need for stimulating, exciting play and exploration of the outer (social and instrumental) world" (p. 196). Although other, more recent studies have also shown results consistent with this hypothesis (e.g., Pinto et al., 2015), differences between fathers and mothers will no doubt be more complex than such a traditional sex-role differentiation suggests. Hence, regardless of any mother-father differences, it would be interesting to investigate in greater depth the differential pathways and developmental outcomes related to 'secure base' and 'safe haven' functions of parents. Possibly, variations in 'secure base' functioning forecast other developmental strengths and vulnerabilities through different explanatory mechanisms than do variations in 'safe haven' functioning. Such a broader focus on the differential effects of 'secure base' and 'safe haven' support, not specifically tied to the biological or social roles of mothers and fathers, would also provide a way to cope with the ever increasing complexity and diversity of family structures, including single-parent families, blended, and LGBT parents.

Second, it should be acknowledged that, as children grow older, their social world expands beyond the family. When children enter school, for instance, their teachers also take a role as ad-hoc or temporary attachment figures, providing children with 'secure base' and 'safe haven' support in the school context (Verschueren \& Koomen, 2012). Also, the significance of peers increases as children move through childhood and adolescence (Rubin, Bukowski, \& Bowker, 2015). All of these social relationships play an additional important role in children's socio-emotional development. One of our own studies showed, for instance, 
that different domains of the self-concept were predicted by different social relationships. Specifically, academic self-concept was related to teacher-child relationship quality, social self-concept to peer acceptance, and general self-concept or global self-esteem to the quality of attachment to mother (Verschueren, Doumen, \& Buyse, 2012). Although these findings suggest domain-specific associative links between children's representations of self and their (representations of) significant social relationships, further research is still warranted. Thus, we join Thompson and Raikes (2003) in their call for more research on how influences of multiple attachment (and other) relationships converge to impact child development.

Third, attachment research has predominantly focused on studying individual differences in attachment quality. Research on father-child attachment has been characterized by the same focus. Although this is important work, we need much more research and scholarly work on the normative development of father-child attachment as well. Does the use of fathers as a 'safe haven' generally decline when children move from childhood to adolescence? Our own work on the development of children's perceptions of attachment security with mother and father from Grade 3 to Grade 6 suggested that this may be the case for girls in particular (Verschueren \& Marcoen, 2005). In contrast, for mother-child attachment, an increase in perceived attachment security (i.e., safe haven use) was found. Maybe the stresses accompanying pubertal maturity temporarily lead girls to rely more on their mothers, rather than their fathers, as a source of comfort and reassurance. At the same time, when moving to early adolescence, children may be more in need of caregivers who encourage them to try new things and to pursue their goals and plans. In this way, the role of 'secure base' may gain relative importance in early adolescence, perhaps especially for fathers. These and other normative changes in attachment functions and their implications remain important topics for future research.

\section{References}


Ainsworth, M. D. S. (1990). Some considerations regarding theory and assessment relevant to attachments beyond infancy. In M. T. Greenberg, K. Cicchetti, \& E. M. Cumming (Eds.), Attachment in the preschool years: Theory, research and intervention (pp. 463488). Chicago: University of Chicago Press.

Bretherton, I. (2010). Fathers in attachment theory and research: A review. Early Child Development and Care, 180, 9-23.

Cassidy, J. (1988). Child-mother attachment and the self in six-year-olds. Child Development, $59,121-134$.

Goodvin, R., Meyer, S., Thompson, R., \& Hayes, R. (2008). Self-understanding in early childhood: Associations with child attachment security and maternal negative affect. Attachment \& Human Development, 10, 433-450. Doi: 10.1080/14616730802461466.

Grossmann, K., Grossmann, K., Fremmer-Bombik, E., Kindler, H., Scheuerer-English, H., \& Zimmerman, P. (2002). The uniqueness of the child-father attachment relationship: Fathers' sensitive and challenging play as a pivotal variable in a 16-year longitudinal study. Social Development, 11, 307-331. Doi: 10.1111/1467-9507.00202.

Kerns, K. A., Mathews, B. L., Koehn, A. J., Williams, C. T., \& Siener-Ciesla, S. (2015). Assessing both safe haven and secure base support in parent-child relationships. Attachment \& Human Development, 17, 337-353. Doi: $10.1080 / 14616734.2015 .1042487$

Kochanska, G., \& Kim, S. (2013). Early attachment organization with both parents and future behavior problems: From infancy to middle childhood. Child Development, 84, 283296. doi:10.1111/j.1467-8624.2012.01852.x

Pinto, A., Veríssimo, M., Gatinho, A., Santos, A.J., \& Vaughn, B.E. (2015). Direct and indirect relations between parent-child attachments, peer acceptance, and self-esteem 
for preschool children. Attachment \& Human Development, 17, 586-598.

doi:10.1080/14616734.2015.1093009.

Rubin, K. H., Bukowski, W. M., \& Bowker, J. C. (2015). Children in Peer Groups. In R. M. Lerner (Ed.), Handbook of Child Psychology and Developmental Science ( $7^{\text {th }}$ ed.) (pp. 175-220). New York: Wiley.

Steele, H., \& Steele, H. (2005). Understanding and resolving emotional conflict: The London parent-child project. In K. E. Grossmann, K. Grossmann, \& E. Waters (Eds.), Attachment from infancy to adulthood: The major longitudinal studies (pp. 137-164). New York, NY: Guilford Press.

Thompson, R. A., \& Raikes, H. A. (2003). Toward the next quarter-century: Conceptual and methodological challenges for attachment theory. Development and Psychopathology, 15, 691-718. Doi: 10.1017/S0954579403000348.

Verschueren, K., Doumen, S., \& Buyse, E. (2012). Relationships with mother, teacher, and peers: unique and joint effects on young children's self-concept. Attachment \& Human Development, 14, 233-248. doi:10.1080/14616734.2012.672263

Verschueren, K., \& Koomen, H. M. Y. (2012). Teacher-child relationships from an attachment perspective. Attachment \& Human Development, 14, 205-211. doi:10.1080/14616734.2012.672260

Verschueren, K., \& Marcoen, A. (1999). Representation of self and socioemotional competence in kindergartners: Differential and combined effects of attachment to mother and to father. Child Development, 70, 183-201.

Verschueren, K., \& Marcoen, A. (2005). Perceived security of attachment to mother and father: Developmental differences and relations to self-worth and peer relationships at school. In K. Kerns \& R. Richardson (Eds.), Attachment in middle childhood (pp. 212230). New York: Guilford Press. 
Verschueren, K., Marcoen, A., \& Schoefs, V. (1996). The internal working model of the self, attachment, and competence in five-year-olds. Child Development, 67, 2493-2511.

Yeung, J., Sandberg, J., Davis-Kean, P., \& Hofferth, S. (2001). Children's time with fathers in intact families. Journal of Marriage and the Family, 63, 136-154.

http://doi.org/10.1111/j.1741-3737.2001.00136.x 